\title{
Transfer of 15-Lipoxygenase Gene into Rabbit lliac Arteries Results in the Appearance of Oxidation-specific Lipid-Protein Adducts Characteristic of Oxidized Low Density Lipoprotein
}

\author{
Seppo Ylä-Herttuala, ${ }^{\star \neq}$ Jukka Luoma, ${ }^{*}$ Helena Viita, ${ }^{\star}$ Timo Hiltunen, ${ }^{\mathbf{\$}}{ }^{||}$Tero Sisto, ${ }^{\mathbf{1}}$ and Tapio Nikkari ${ }^{\mathbf{\$}}$ \\ *A. I. Virtanen Institute, University of Kuopio; ${ }^{\ddagger}$ Department of Medicine, Kuopio University Hospital, FIN-70211 Kuopio, Finland; \\ ${ }^{\S}$ Department of Medical Biochemistry, Medical School, University of Tampere; "Department of Clinical Chemistry, \\ and 'Department of Surgery, Tampere University Hospital, FIN-33101 Tampere, Finland
}

\begin{abstract}
Oxidized low density lipoprotein (LDL) possesses several atherogenic properties. The mechanisms by which LDL becomes oxidized in vivo remain unknown, but previous studies have suggested that 15-lipoxygenase may be one of the factors involved in the initiation of LDL oxidation in the arterial wall. 3 wk after a retrovirus-mediated 15-lipoxygenase gene transfer into iliac arteries of normocholesterolemic rabbits there was a threefold increase in 15-lipoxygenase activity but no signs of LDL oxidation. However, when animals were made moderately hypercholesterolemic by feeding a $0.13 \%$ cholesterol diet for $2-3$ wk starting from day 4 after the gene transfer, oxidation-specific lipid-protein adducts characteristic of oxidized LDL were detected in 15lipoxygenase-transduced arteries. Control experiments in which contralateral iliac arteries were transduced with $\beta$ galactosidase-containing retroviruses showed only occasional signs of the presence of oxidation-specific adducts. The results support the hypothesis that products derived from the 15-lipoxygenase activity are involved in the induction of LDL oxidation within the arterial wall, provided that sufficient concentrations of lipoproteins are present in the artery. (J. Clin. Invest. 1995. 95:2692-2698.) Key words: atherosclerosis $\cdot \beta$-galactosidase $\cdot$ gene transfer $\cdot$ retroviruses
\end{abstract}

\section{Introduction}

A growing body of evidence suggests that oxidative modification of LDL plays an important role in atherogenesis (1). Oxidized LDL is present in atherosclerotic lesions $(2-7)$, it is avidly metabolized by macrophages ( 8 ), cytotoxic to various cell types (9), chemotactic for blood monocytes (10), and induces formation of autoantibodies against oxidation-specific lipid-protein epitopes $(4,11,12)$. Inhibition of LDL oxidation also decreases the rate of development of atherosclerotic lesions

Address correspondence to Seppo Ylä-Herttuala, M.D., A. I. Virtanen Institute, University of Kuopio, P. O. Box 1627, FIN-70211, Finland. FAX: 71-163-030.

Received for publication 15 November 1994 and in revised form 30 January 1995.

J. Clin. Invest.

(C) The American Society for Clinical Investigation, Inc.

0021-9738/95/06/2692/07 \$2.00

Volume 95, June 1995, 2692-2698 in experimental animals $(1,13)$. However, mechanisms leading to LDL oxidation in vivo remain unknown.

Lipoxygenases (LO) ${ }^{1}$ are a family of enzymes which catalyze the deoxygenation of polyenoic fatty acids containing at least one 1,4-cis, cis-pentadiene structure, yielding corresponding fatty acid hydroperoxides as reaction products $(14,15)$. So far, 5-, 12-, and 15-LO enzymes have been cloned from mammalian tissues $(14,15)$. All biological functions of LOs are not yet known, but 15-LO seems to play a role in the peroxidation and breakdown of mitochondrial and other cellular membranes during reticulocyte maturation (16). In vitro studies have suggested that $15-\mathrm{LO}$, but not $5-\mathrm{LO}(17,18)$, may be one of the factors involved in the initiation of LDL oxidation. LDL treated with soybean 15 -LO $(9,19)$ or recombinant human 15LO (20) closely resembles oxidized LDL; enrichment of LDL with LO-derived peroxidation products promotes LDL oxidation in the presence of transition metals $(21,22)$; and several lipoxygenase inhibitors block cell-induced oxidation of LDL $(17,23-25)$. It is not known whether 15-LO induces LDL oxidation in vivo, but 15-LO mRNA and protein are expressed in macrophage-rich areas of atherosclerotic lesions in the same areas which contain epitopes characteristic of oxidized LDL $(26,27)$. Atherosclerotic lesions also show higher levels of 15LO enzyme activity and reaction products than corresponding normal arteries $(28,29)$. Accordingly, it would be important to establish experimental models in which 15-LO expression is induced in the arterial wall. If $15-\mathrm{LO}$ plays a role in LDL oxidation in vivo it should be possible to test the hypothesis by transferring 15-LO gene into normal arteries and determine whether this leads to the formation of epitopes characteristic of oxidized LDL.

To create such a model and to evaluate the role of 15-LO in the development of early atherosclerotic changes, we used a retrovirus-mediated 15-LO gene transfer into rabbit iliac arteries (30). This model gives an opportunity for studying the effects of the gene in an anatomically defined portion of an artery (3033) and offers a means for examining the role of 15-LO in vivo, as there is controversy regarding the role of $15-\mathrm{LO}$ in inducing LDL oxidation in cell culture systems (34). It was found that retrovirus-mediated gene transfer led to the expression of 15-LO in the transduced arteries and that in animals fed a $0.13 \%$ cholesterol diet 15 -LO-transduced arteries exhibited a higher susceptibility to LDL oxidation than control iliac arteries transduced with $\beta$-galactosidase-containing retroviruses.

1. Abbreviations used in this paper: LO, lipoxygenases; LTR, long terminal repeat; MDA, malondialdehyde. 
A

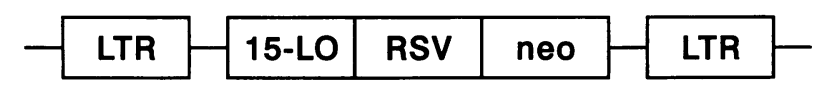

B

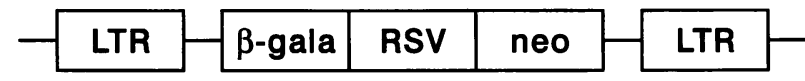

Figure 1. Retroviral plasmids. (A) A SalI-BglII fragment (nucleotides 1-2245) of the human reticulocyte 15-LO cDNA (35) was cloned into a plasmid (37) containing a Moloney murine leukemia virus LTR cassette with a neomycin resistance gene ( $n e o$ ) expressed from an internal Rous sarcoma virus ( $R S V$ ) promoter. $(B)$ A full-length $E$. coli $\beta$-galactosidase cDNA (36) was cloned into the same retroviral plasmid and used as a control vector (37). 15-LO and $\beta$-galactosidase are expressed from the constructs by the $5^{\prime}$-LTR promoter. Poly A signals are provided by the $3^{\prime}$-LTR. The rest of the plasmid (not shown) is derived from pBR322.

\section{Methods}

Human reticulocyte 15-LO cDNA (35) or Escherichia coli $\beta$-galactosidase (lacZ) cDNA (36) were cloned into a plasmid containing a Moloney murine leukemia virus long terminal repeat (LTR) cassette with a neomycin resistance gene expressed from an internal Rous sarcoma virus promoter (37) (Fig. 1) . 15-LO and $\beta$-galactosidase were expressed from the constructs by the 5 '-LTR promoter. Poly A signal and repeated motifs presumably associated to translational repression (38) were omitted from the $3^{\prime}$ untranslated end of 15-LO cDNA (Fig. 1). Ecotropic $(42)(39)$ and amphotropic (PA317) (40) producer cell lines were established using standard techniques (41). Amphotropic cell lines produced replication-deficient retroviruses, which were able to transduce 15-LO and $\beta$-galactosidase activity into fibroblasts and smooth muscle cells in vitro ${ }^{2}$ (Table I). Before use, the retroviruses were concentrated by a polyethylene glycol precipitation, and titers of the virus preparations were determined (41). Concentrated virus stocks were free of helper virus activity as analyzed by the inability of concentrated viruses to spread the infection in F209 fibroblasts (41).

Gene transfer was done in 16 4-6-mo-old New Zealand White rabbits. 10 rabbits were maintained on normal chow. To induce a moderate increase in plasma cholesterol level and to increase lipoprotein influx into the artery wall, six rabbits were fed a cholesterol-enriched diet $(0.13 \% \mathrm{wt} / \mathrm{wt})$ for $2-3 \mathrm{wk}$, starting $4 \mathrm{~d}$ after the gene transfer. Animals were anesthetized using fentanyl-fluanisone $(0.3 \mathrm{ml} / \mathrm{kg}) /$ midatzolam ( 1 $\mathrm{mg} / \mathrm{kg}$ ). 1-cm unbranched segments of the external iliac arteries were exposed through laparotomy. A cannula (22G Insyte-W; Becton Dickinson, Mountain View, CA) was inserted into the femoral artery and advanced to the distal end of the experimental area. Proximal and distal ends of the experimental area were closed by removable ligatures and micro Bulldog clamps. A spinal needle (27G; Becton Dickinson) was placed inside the $22 \mathrm{G}$ cannula and the experimental area was flushed several times with lactated Ringer solution. Replication-deficient retroviruses (titers $2-10 \times 10^{5} \mathrm{cfu} / \mathrm{ml}$ ) were placed directly into the artery through the spinal needle and left in place for $30 \mathrm{~min}$. Care was taken not to exceed $150 \mathrm{mmHg}$ intraluminal pressure. After the experiment, retroviruses were removed, arteries were flushed with Ringer solution, and the circulation was reestablished. Frozen aliquots of the same virus

2. Viita, H., T. Kaunismäki, M. Laukkanen, T. Nikkari, and S. YläHerttuala, manuscript in preparation.
Table I. 15-LO Activity in the Transduced PA317 Fibroblasts and Rabbit Aortic Smooth Muscle Cells

\begin{tabular}{lc}
\hline \multicolumn{1}{c}{ Cell line } & $\begin{array}{c}\text { Hydroxyoctadecanoic } \\
\text { acid production* }\end{array}$ \\
\hline & $n g / m g$ cell protein/15 min \\
PA317 cells & \\
$\quad$ Control (untransduced cells) & 36.3 \\
Control ( $\beta$-galactosidase-transduced & \\
clone LZ3) & 27.1 \\
15-LO-transduced (clone ALO17) & 410.8 \\
Smooth muscle cells & 11.3 \\
Control (untransduced cells) & 524.0 \\
15-LO-transduced (clone SMCLO17) & \\
\hline
\end{tabular}

15-LO activity was measured as described in Methods after incubation of the cells with $50 \mu \mathrm{M}$ linoleic acid at $37^{\circ} \mathrm{C}$ for $15 \mathrm{~min}$. * Analyses were done in duplicates and are representative of results obtained with transduced cell lines ${ }^{2}$.

concentrates (ALO17 for 15-LO; LZ915 for $\beta$-galactosidase) were used in the study.

In each animal one iliac artery was transduced with the 15-LOcontaining retroviruses. In all but two animals, the contralateral iliac artery was handled exactly in the same way and transduced with the same retroviruses containing E. coli $\beta$-galactosidase instead of 15-LO. Prophylactic heparin and G-penicillin treatments were used in all experiments. Animals were free of helper virus production throughout the experiments, as judged by the absence of reverse transcriptase activity in plasma and urine samples (41). Fasting plasma cholesterol levels were measured with enzymatic methods (Boehringer Mannheim, Mannheim, Germany). All experiments were approved by the Experimental Animal Committee of the Universities of Kuopio and Tampere.

After the experimental period, arteries were either perfusion-fixed or perfused with phosphate-buffered saline and used for in situ hybridization, immunocytochemistry, and/or gas chromatographic analysis. Briefly, arteries were perfusion-fixed with $4 \%$ paraformaldehyde $/ 5 \%$ sucrose containing $1 \mathrm{mM}$ EDTA and $50 \mu \mathrm{M}$ butylated hydroxytoluene as antioxidants, embedded in paraffin and/or OCT compound (Miles Inc., Kankakee, IL), and used for in situ hybridization and immunocytochemistry (26). In situ hybridization was done on a set of serial sections as described $(26,27)$. Briefly, ${ }^{35}$ S-UTP-labeled antisense and sense riboprobes for human reticulocyte 15-LO were synthesized from pBluescript vectors (Stratagene, La Jolla, CA) using T3 and T7 RNA polymerases (Promega Corp., Madison, WI) and applied on pretreated tissue sections $\left(6 \times 10^{6} \mathrm{cpm} / \mathrm{ml}\right)$ for $14 \mathrm{~h}$ at $53^{\circ} \mathrm{C}$. The final wash after the hybridization was at $55^{\circ} \mathrm{C}$ in $0.1 \times \mathrm{SSC}$ for $30 \mathrm{~min}$. Autoradiography (NTB-2; Eastman-Kodak Co., Rochester, NY) was used for the signal detection $(26,27)$.

Immunocytochemistry was done as described $(26,42)$. Both iliac arteries from the same animal were always immunostained simultaneously (avidin-biotin-horseradish peroxidase system; Vector Labs, Inc., Burlingame, CA) in a rigorously standardized way $(26,42)$. Controls for the immunostainings included incubations with irrelevant class- and species-matched immunoglobulins and incubations where primary antibodies were omitted. Five serial sections taken from the middle portion of the experimental area were evaluated per artery for each of the antibodies. Immunostainings were evaluated by one examiner without knowledge of the origin of the samples. $\beta$-Galactosidase activity was measured by X-gal staining as described (30). To avoid any possible staining of endogenous $\beta$-galactosidase activity present in macrophages, color development was only allowed to proceed for $6 \mathrm{~h}$.

The following antibodies were used for the immunostainings: CD31 
Table II. Frequency of Successful Gene Transfer and the Presence of Oxidized LDL in Rabbit Iliac Arteries 2-3 wk after a Direct Retrovirus-mediated Gene Transfer

\begin{tabular}{|c|c|c|c|c|}
\hline \multirow{2}{*}{$\begin{array}{l}\text { Iliac arteries transduced with } \\
\text { retroviruses containing }\end{array}$} & \multicolumn{2}{|c|}{ Number of arteries positive for transduced gene* } & \multicolumn{2}{|c|}{ Number of arteries positive for oxidized $\mathrm{LDL}^{\ddagger}$} \\
\hline & Normocholesterolemic & Moderately hypercholesterolemic & Normocholesterolemic & Moderately hypercholesterolemic \\
\hline \multirow[t]{2}{*}{ 15-LO } & 7 & 5 & 1 & 4 \\
\hline & $(n=10)$ & $(n=6)$ & $(n=7)$ & $(n=5)$ \\
\hline \multirow[t]{2}{*}{$\beta$-Galactosidase } & 6 & 6 & 0 & 1 \\
\hline & $(n=8)$ & $(n=6)$ & $(n=6)$ & $(n=6)$ \\
\hline
\end{tabular}

$(n)$ indicates the total number of analyzed arteries. ${ }^{*}$ Based on positive immunostaining for 15-LO (anti-human 15-LO antiserum [27]; dilution $1: 1,000$ ) or $\beta$-galactosidase activity (X-gal staining). ${ }^{\ddagger}$ Based on positive immunostaining for oxidation-specific lipid-protein adducts characteristic of oxidized LDL (antiserum MAL-2 [4]; dilution 1:500); immunostainings for oxidized epitopes were only evaluated in the arteries where gene transfer was successful.

mAb specific for endothelial cells (DAKO, Copenhagen, Denmark); HHF-35 mAb specific for smooth muscle cells (43; Enzo Biochem Inc., New York); RAM-11 mAb specific for rabbit macrophages (44) kindly donated by Dr. Allen Gown (University of Washington, Seattle, WA); MAL-2 antiserum (4) made against malondialdehyde (MDA)-modified LDL and specific for MDA-lysine adducts; MB-47 mAb specific for apoprotein B-100 present in LDL and remnant/ $\beta$-very low density lipoproteins (45); anti-human reticulocyte 15-LO antiserum (27) which does not crossreact with 5-LO but which crossreacts with rabbit macrophage 15-LO at 1:100-1:500 dilutions. MB-47, MAL-2, and 15-LO antibodies were kindly donated by Dr. Joseph L. Witztum (University of California, San Diego, Atherosclerosis SCOR program).

Intima/media thickness ratios were measured from five randomly selected sections per artery using a standard morphometry (46). Measurements were done from all animals where gene transfer was successful. 15-LO reaction products from isolated intima-medias of two normocholesterolemic and two moderately hypercholesterolemic animals were assayed with gas chromatography after reduction to hydroxyoctadecanoic acid (47). Linoleic acid-derived reaction products (i.e., hydroxyoctadecanoic acid) were used as an indicator of 15-LO activity since they are present in higher concentrations and are more stable than arachidonic acid derivatives (15). 15-LO activity in the transduced cell lines was measured after incubation of the mechanically disrupted cells with $50 \mu \mathrm{M}$ linoleic acid for $15 \mathrm{~min}$ at $37^{\circ} \mathrm{C}$. Linoleic acid-derived reaction products were quantified with gas chromatography after reduction to hydroxyoctadecanoic acid. More than $90 \%$ of the hydroxyoctadecanoic acid produced consisted of the 13-isomer, which is the specific reaction product of 15-LO when linoleic acid is used as a substrate ${ }^{2}(47)$.

\section{Results}

Before in vivo experiments, retroviruses were tested for their ability to transduce eukaryotic cells in vitro. As shown in Table I, rabbit aortic smooth muscle cells transduced with 15-LOcontaining retroviruses showed a marked increase in 15-LO activity. A similar increase was seen in PA317 fibroblasts after transduction with ecotropic 15-LO-containing retroviruses, whereas no increase was seen in $\beta$-galactosidase-transduced cells. 15-LO-transduced cells contained human 15-LO mRNA and immunoreactive protein, as analyzed by Northern blotting and Western blotting, respectively, whereas no 15-LO mRNA or protein was detected in untransduced smooth muscle cells. ${ }^{2}$

After in vitro studies, New Zealand White rabbit iliac arteries were transduced with 15-LO-containing retroviruses. To control for possible effects of the viral infection per se, contralateral iliac arteries were treated in the same manner, but were transduced with the virus containing $E$. coli $\beta$-galactosidase instead of 15-LO. 2-3 wk after the gene transfer, histochemically demonstrable $\beta$-galactosidase activity was present in 12 of the 14 transduced control arteries (Table II). 15-LO protein was detected by immunostaining in 12 of the 16 transduced arteries (Table II), and there was a threefold increase in the chemically assayed arterial content of oxidized linoleic acid reaction products, which were used as an indicator of 15-LO activity (Table III).

An example of the transduced gene expression is shown in Fig. 2. $\beta$-Galactosidase activity was detected in $\beta$-galactosidase-transduced arteries (Fig. $2 a$ ), whereas it was not present in the 15-LO-transduced arteries (Fig. $2 d$ ). 15-LO immunoreactivity and mRNA were detected in the 15-LO-transduced arteries (Fig. 2, $e$ and $f$ ). No 15-LO protein (Fig. $2 b$ ) or mRNA (data not shown) was present in the $\beta$-galactosidasetransduced control arteries. Based on the number of 15-LOpositive cells and the total number of stained nuclei in randomly selected tissue sections, it was estimated that $<1 / 500$ cells in the intima-media expressed $\beta$-galactosidase or $15-\mathrm{LO}$. $15-\mathrm{LO}$ expression declined over time in the transduced arteries but was still detectable $6 \mathrm{wk}$ after the operation (data not shown).

Table III. Intima-Media Thickness Ratios and the Content of Linoleic Acid-derived Reaction Products, Which Were Used as an Indicator of 15-LO Activity in Rabbit Iliac Arteries 2-3 wk after a Successful Retrovirus-mediated Gene Transfer

\begin{tabular}{lcc}
\hline $\begin{array}{c}\text { Iliac arteries } \\
\text { transduced with } \\
\text { retroviruses containing }\end{array}$ & $\begin{array}{c}\text { Intima-media } \\
\text { thickness ratio } \\
(\text { mean } \pm \text { SD })\end{array}$ & $\begin{array}{c}\text { Hydroxyoctadecanoic acid } \\
\text { content }(\% \text { of control, } \\
\text { mean } \pm \text { SD) }\end{array}$ \\
\hline 15 -LO & $0.44 \pm 0.21$ & $324 \pm 180$ \\
$\beta$-Galactosidase & $(n=12)$ & $(n=4)$ \\
& $0.47 \pm 0.23$ & 100 \\
$(n=12)$ & $(n=4)$
\end{tabular}

(n) indicates the number of analyzed arteries. Arteries analyzed for the content of hydroxyoctadecanoic acids include two normocholesterolemic and two moderately hypercholesterolemic animals. The content of hydroxyoctadecanoic acids in the $\beta$-galactosidase-transduced control arteries was $77 \pm 49$ (SD) $\mathrm{ng} / \mathrm{mg}$ dry defatted tissue. For comparison, the content of hydroxyoctadecanoic acids in four unoperated abdominal aortas was $32 \pm 23(\mathrm{SD}) \mathrm{ng} / \mathrm{mg}$ dry defatted tissue. 

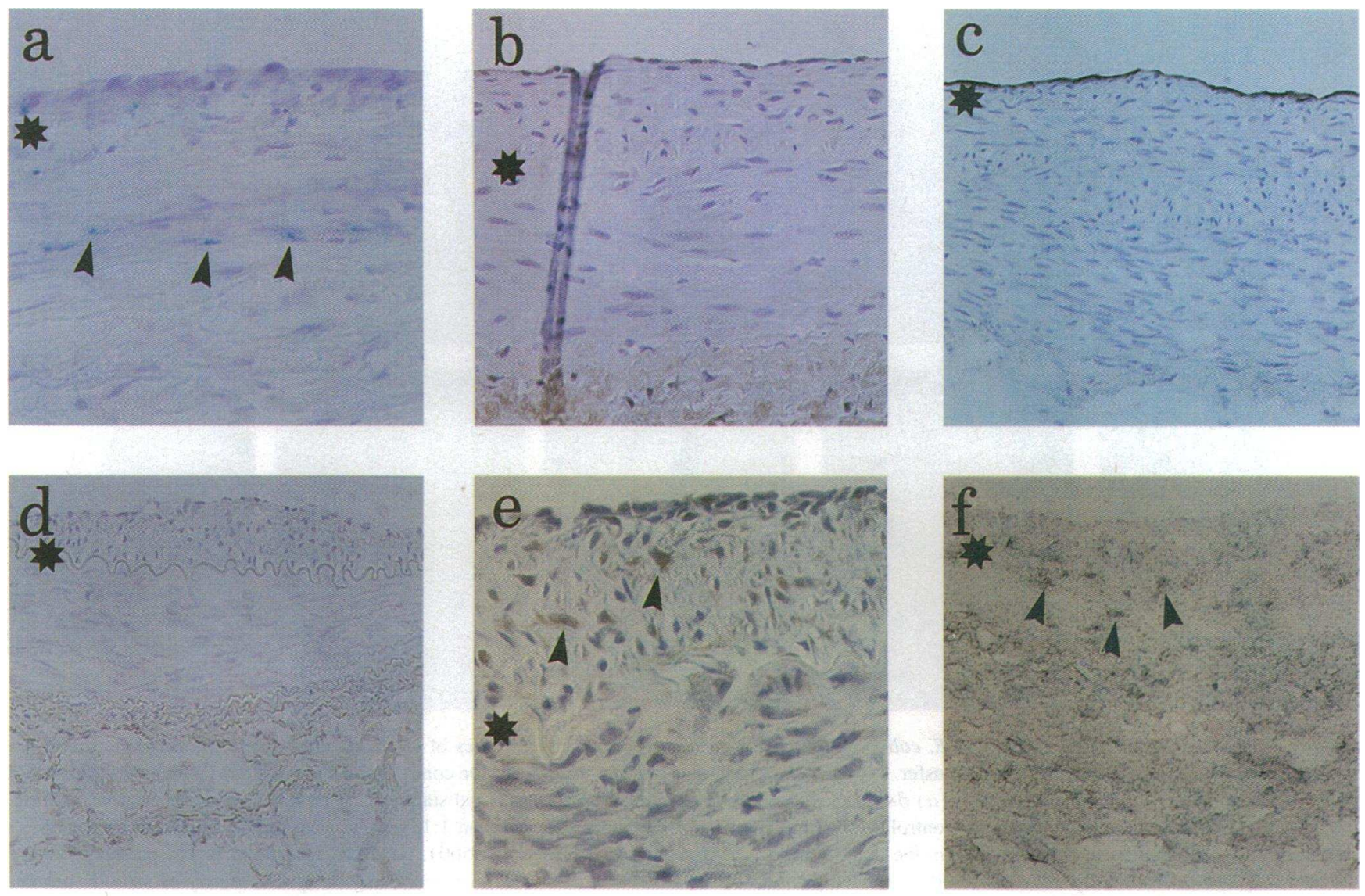

Figure 2. Expression of human 15-LO and $E$. coli $\beta$-galactosidase in the transduced iliac arteries of a normocholesterolemic rabbit 3 wk after a direct retrovirus-mediated gene transfer. $(a-c)$ Immunostainings of serial sections of the contralateral control artery, which was transduced with $\beta$-galactosidase-containing retrovirus. (a) $\beta$-Galactosidase activity in the arterial wall (X-gal staining). Arrowheads indicate positive cells. (b) No 15-LO protein was detected in the transduced control artery (anti-human 15-LO antiserum, dilution 1:1,000). (c) Endothelial layer was present in the artery after the experimental period (CD31 antibody, dilution 1:50). $(d, e)$ Immunostainings of serial sections of the iliac artery transduced with the human 15-LO-containing retrovirus. $(d)$ No $\beta$-galactosidase activity was present in the arterial wall (X-gal staining). (e) Expression of 15-LO protein in the transduced artery (anti-human 15-LO antiserum, dilution 1:1,000). Arrowheads indicate positive staining for 15-LO. $(f)$ Expression of 15-LO mRNA in the 15-LO-transduced artery. A ${ }^{35}$ S-UTP-labeled 15-LO antisense riboprobe was used for the hybridization, followed by autoradiography. Arrowheads indicate cells positive for 15-LO mRNA. Control hybridization with a sense probe gave no signal (data not shown). A star indicates the boundary between intima and media. Hematoxylin counter stain, except in $f$, which was counterstained with hematoxylin and eosin. Original magnifications of $400(a$ and $e), 300(b), 200(c$ and $f)$, and $100(d)$.

Endothelial layer appeared morphologically intact in the transduced arteries (Fig. $3 c$ ). However, it is likely that some arterial injury was produced by the gene transfer procedure, since in preliminary experiments we found that catheterization alone or together with transduction using $\beta$-galactosidase-containing retroviruses always caused diffuse intimal thickening. Similar thickenings were produced in this study, as indicated by an increased intima-media thickness ratio in the iliac arteries; however, there was no difference between $\beta$-galactosidaseand 15-LO-transduced arteries (Table III). The thickening was mainly due to the proliferation of smooth muscle cells. An example is shown in Fig. $3 e$. The cause of the vascular injury remains unknown. However, the findings may suggest that 15LO activity and/or LDL oxidation may not play a significant role in smooth muscle cell proliferation and neointima formation.

After successful transduction of seven normocholesterolemic rabbits with $15-\mathrm{LO}$, only one animal showed a weak staining for oxidation-specific lipid-protein adducts in the iliac artery 3 wk after the gene transfer (Table II). Since the arterial wall of a normal rabbit contains hardly any apoprotein Bcontaining lipoproteins, we used a $0.13 \%$ cholesterol diet to increase the influx of plasma lipoproteins into the arterial wall thickened by the manipulation (Fig. 3, $d$ and $i$ ). The diet was started $4 \mathrm{~d}$ after the gene transfer. 2-3 wk after the operation, four of the five arteries successfully transduced with 15-LO contained immunostaining for oxidation-specific lipid-protein adducts in the intima-media, whereas only one of the six contralateral control iliac arteries successfully transduced with $\beta$-galactosidase contained immunostaining for these adducts (Fig. $3, c$ and $h$, Table IV). Staining pattern was different in the experimental and control arteries: the intima-media of 15-LOtransduced arteries usually contained areas and groups of cells positive for both 15-LO protein and oxidation-specific lipidprotein adducts (Fig. 3, $g$ and $h$ ), whereas no such association was seen in the one control artery which stained positive for 

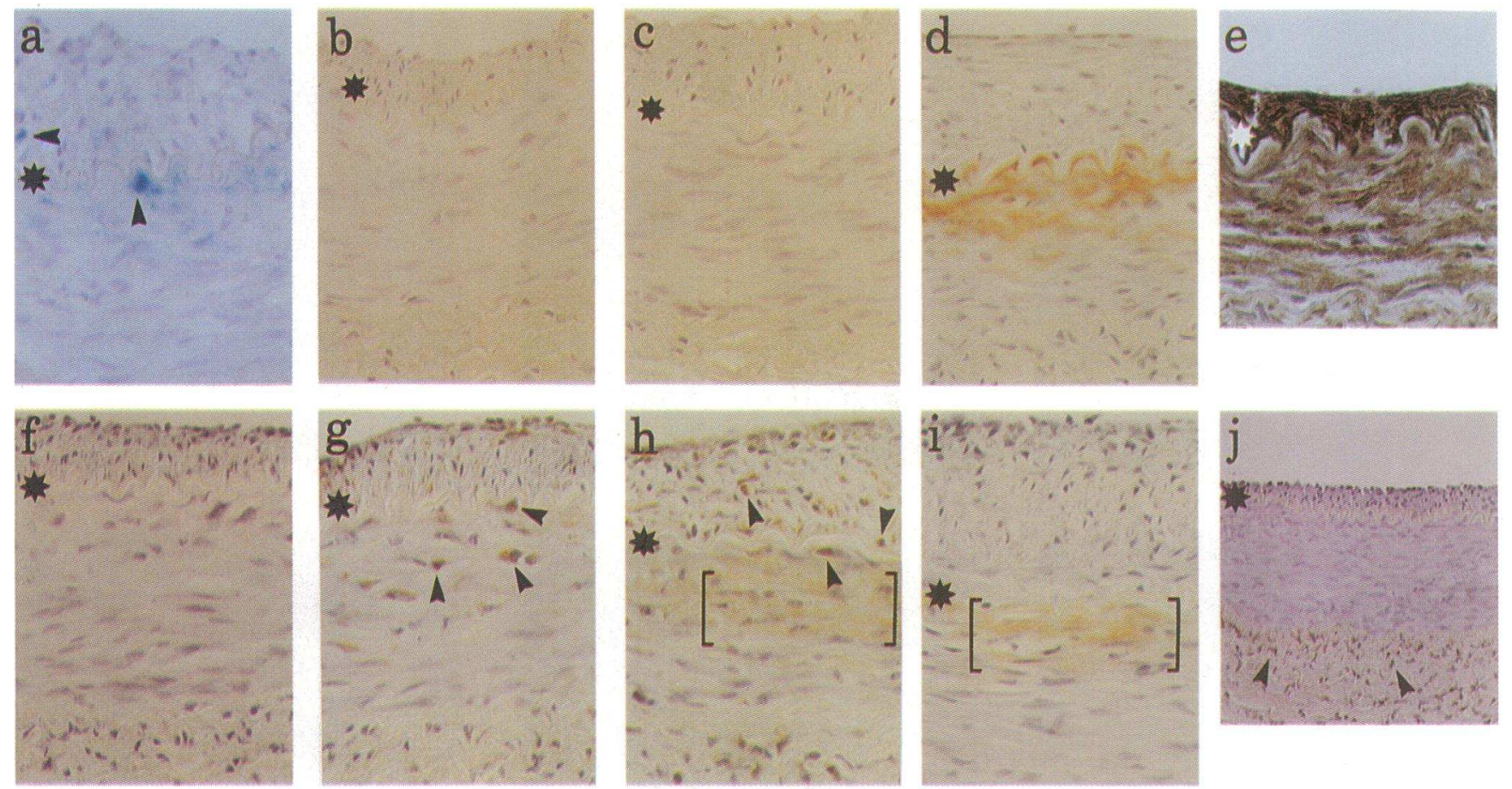

Figure 3. Expression of human 15-LO and $E$. coli $\beta$-galactosidase in the transduced iliac arteries of a moderately hypercholesterolemic rabbit 3 wk after a direct retrovirus-mediated gene transfer. $(a-e)$ Immunostainings of serial sections of the contralateral control artery, which was transduced with $\beta$-galactosidase-containing retrovirus. (a) $\beta$-Galactosidase activity in the arterial wall (X-gal staining). Arrowheads indicate positive staining. (b) No 15-LO protein was detected in the control artery (anti-human 15-LO antiserum, dilution 1:1,000). (c) No oxidized LDL or oxidationspecific lipid-protein adducts were detected in the control artery (MAL-2 antiserum, dilution 1:500). (d) LDL apoprotein B was present in the arterial wall (MB-47 antibody, dilution 1:500). (e) Manipulation of the arteries produced intimal thickening composed mostly of smooth muscle cells (HHF-35 antibody, dilution 1:500). $(f-j)$ Immunostainings of serial sections of the iliac artery transduced with the human 15-LO-containing retrovirus. $(f)$ Nonimmune control for the immunostainings. $(g)$ Expression of 15-LO protein in the transduced artery (anti-human 15-LO antiserum, dilution 1:1,000). Arrowheads indicate positive staining for 15-LO. $(h)$ Oxidized LDL and oxidation-specific lipid-protein adducts in the transduced artery (MAL-2 antiserum, dilution 1:500). Arrowheads indicate cells positive for oxidized epitopes. Extracellular staining for oxidized epitopes is indicated by brackets. (i) LDL apoprotein B immunostaining appeared in the same area which contained oxidized LDL, as is shown in $h$ (MB-47 antibody, dilution 1:500). Extracellular staining is indicated by brackets. $(j)$ No macrophages were detected in the thickened intima, whereas they were usually present in adventitia (RAM-11 antibody, dilution 1:500). Arrowheads indicate positive staining for macrophages. A star indicates the boundary between intima and media. Hematoxylin counter stain. Original magnifications of $400(a-i)$ and $200(j)$.

oxidized adducts (animal 16, Table IV). In several areas of the 15-LO-transduced arteries, oxidized epitopes colocalized with immunostaining specific for apoprotein B (Fig. 3, $h$ and $i$ ). Very few macrophages were present in the thickened intimas of all studied animals (Fig. $3 j$ ), which makes it highly unlikely that these cells were responsible for lipoprotein oxidation. As judged by immunostaining of serial sections, most of the cells expressing the transduced 15-LO appeared to be smooth muscle cells.

\section{Discussion}

The mechanism whereby LDL is oxidized in vivo remains unknown. It is likely that several pathways can lead to the appearance of oxidized LDL in the arteries $(1,48)$. In vitro and in vivo studies have suggested that 15-LO may be one of the factors involved in the initiation of LDL oxidation in the arterial wall (19-27). To further assess the possible role of 15-LO in LDL oxidation in vivo, we used retrovirus-mediated 15-LO gene transfer into rabbit iliac arteries (30). The aim of the study was to see whether the expression of 15-LO in the transduced arteries leads to the formation of oxidation-specific lipid-protein adducts characteristic of oxidized LDL.

Major limitations of this approach in rabbits appear to be the production of vascular injuries during arterial manipulation and the low efficiency of retrovirus-mediated gene transfer in the arterial wall. Possible effects caused by the replicationdeficient retroviruses and the catheterization of arteries were controlled by transducing contralateral control iliac arteries with the same retrovirus containing $\beta$-galactosidase instead of 15 LO. Diffuse intimal thickening was always observed in the transduced arteries. Similar findings were obtained in preliminary experiments where the arteries were catheterized and incubated with Ringer solution for 30 min (data not shown). The thickening was mainly due to the proliferation of smooth muscle cells, although the exact nature of the injurious procedure/agent remains unknown. However, this was not considered harmful since the presence of intimal thickening resembles the situation in human arteries, where diffuse intimal thickening is always present and forms a microenvironment for LDL retention, prolonging LDL half-life in the intima-media, and making LDL more susceptible for oxidative damage $(1,49)$. 
Table IV. 15-LO and Oxidized LDL Immunostaining in Iliac Arteries of Moderately Hypercholesterolemic Rabbits after a Direct Retrovirus-mediated Gene Transfer

\begin{tabular}{|c|c|c|c|c|c|c|}
\hline \multirow{3}{*}{$\begin{array}{l}\text { Animal } \\
\text { number }\end{array}$} & \multirow{3}{*}{$\begin{array}{l}\text { Killing after the } \\
\text { gene transfer }\end{array}$} & \multirow{3}{*}{$\begin{array}{l}\text { Blood cholesterol* at time } \\
\text { of killing }\end{array}$} & \multicolumn{4}{|c|}{ Iliac arteries successfully transduced with retroviruses containing } \\
\hline & & & \multicolumn{2}{|c|}{ 15-LO } & \multicolumn{2}{|c|}{$\beta$-Galactosidase } \\
\hline & & & $15-\mathrm{LO}^{\ddagger}$ & Oxidized epitopes $^{\ddagger}$ & $15-\mathrm{LO}^{\ddagger}$ & Oxidized epitopes ${ }^{\ddagger}$ \\
\hline & $d$ & mmolliter & & & & \\
\hline 11 & 14 & 3.6 & + & + & 0 & 0 \\
\hline 12 & 16 & 2.5 & $\S$ & $\S$ & 0 & 0 \\
\hline 13 & 16 & 1.7 & + & 0 & 0 & 0 \\
\hline 14 & 19 & 5.4 & + & ++ & 0 & 0 \\
\hline 15 & 23 & 4.7 & ++ & ++ & 0 & 0 \\
\hline \multirow[t]{3}{*}{16} & 23 & 4.8 & + & + & 0 & + \\
\hline & & & \multirow{2}{*}{\multicolumn{2}{|c|}{$P<0.01^{\| \prime}$}} & & 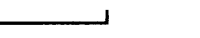 \\
\hline & & & & & \multicolumn{2}{|c|}{$P<0.08^{\|}$} \\
\hline
\end{tabular}

$\S$, Gene transfer was not successful. * Animals were fed with $0.13 \%$ cholesterol diet starting $4 \mathrm{~d}$ after the operation. Plasma cholesterol before the experiment was $1.3 \pm 0.8$ (SD) $\mathrm{mmol} /$ liter. ${ }^{\ddagger}$ Intensity of the immunostaining in intima-media was graded blindly on a scale of 0 (no staining) to +++ (intense staining). "Statistical significance in comparison with the frequency of corresponding immunostaining in $\beta$-galactosidase-transduced arteries (Fisher's exact test, two-tail comparison, SAS Statistical Software Inc., Cary, NC).

The low transduction efficiency with replication-deficient retroviruses is in line with previously published data showing that only a minor fraction of cells can be transduced with this technique (30-33). It is evident that the low transduction efficiency needs to be improved if the technique is used for the delivery of therapeutic substances into the vessel wall. Based on immunocytochemistry and in situ hybridization, 15-LO expression was found in single cells and within discrete groups of cells in the artery. In future, it may be possible to use this model to monitor local changes in the expression of various genes around cells expressing the transduced gene.

The presence of oxidized epitopes in the iliac arteries was detected by immunocytochemical techniques using antibodies raised against MDA-modified LDL which is a model of oxidized LDL (2-4). It should be noted that these antibodies also detect some other MDA-modified proteins, such as MDAalbumin $(4,42)$. We cannot fully exclude a possibility that intracellular immunostaining for oxidation-specific epitopes (which are not associated with MB-47 immunostaining) may be unrelated to lipoprotein oxidation. It should also be pointed out that extracellular immunostaining for oxidized epitopes was not always associated with intracellular staining for oxidationspecific adducts. One possible explanation is that diffusible factors (e.g., radicals) from 15-LO-transduced cells may have initiated lipid peroxidation in lipoproteins trapped in extracellular matrix.

Despite a measurable level of $15-\mathrm{LO}$ expression in the transduced arteries, no oxidation-specific lipid-protein adducts were found in the arterial wall unless the animals were fed a cholesterol-enriched diet. Thus, the results suggest that both the expression of 15-LO and the presence of apoprotein B-containing lipoproteins in the arterial wall were required for the formation of oxidation-specific lipid-protein adducts, since ( $a$ ) 15-LO expression alone did not lead to the appearance of oxidationspecific epitopes in normocholesterolemic animals; $(b)$ except in one animal, $\beta$-galactosidase-transduced control arteries in the cholesterol-fed group did not contain oxidized epitopes; and $(c)$ oxidation-specific epitopes in the 15-LO-transduced arteries tended to colocalize with $15-\mathrm{LO}$ protein and LDL apoprotein B immunostainings.

The results demonstrate that a definite, although modest, increase in 15-LO activity can be achieved in iliac arteries 2-3 wk after the transduction with 15-LO-containing retroviruses. When compared with $\beta$-galactosidase-transduced control iliac arteries, the 15-LO-transduced sites of the intima-media also exhibited a higher susceptibility to LDL oxidation as indicated by positive immunostaining for epitopes characteristic of oxidized LDL. The results support the hypothesis that $15-\mathrm{LO}$ is one of the factors involved in LDL oxidation in the arterial microenvironment (19-27). The model will be useful for the evaluation of localized oxidation-related early steps in the pathogenesis of atherosclerosis.

\section{Acknowledgments}

We thank Drs. Joseph L. Witztum, Daniel Steinberg, Sampath Parthasarathy, Theodore Friedmann, David Benz, Atsushi Miyanohara, and Elliott Sigal for human 15-LO retroviral construct and helpful comments regarding the manuscript, Dr. Tiina Solakivi for plasma cholesterol measurements, Ms. Marja Jousimies and Ms. Mervi Nieminen for technical assistance, and Ms. Eija Kyrölä for typing the manuscript.

This study was supported by grants from The Finnish Academy, the Sigrid Jusélius Foundation, and the Finnish Heart Foundation.

\section{References}

1. Witztum, J. L., and D. Steinberg. 1991. Role of oxidized low density lipoprotein in atherogenesis. J. Clin. Invest. 88:1785-1792.

2. Haberland, M. E., D. Fong, and L. Cheng. 1988. Malondialdehyde-altered LDL occurs in atheroma of Watanabe heritable hyperlipidemic rabbits. Science (Wash. DC). 241:215-218.

3. Ylä-Herttuala, S., W. Palinski, M. E. Rosenfeld, S. Parthasarathy, T. E. Carew, S. Butler, J. L. Witztum, and D. Steinberg. 1989. Evidence for the presence 
of oxidativey modified low density lipoprotein in atherosclerotic lesions of rabbit and man. J. Clin. Invest. 84:1086-1095.

4. Palinski, W., M. E. Rosenfeld, S. Ylä-Herttuala, G. C. Gurtner, S. S. Socher, S. W. Butler, S. Parthasarathy, T. E. Carew, D. Stenberg, and J. L. Witztum. 1989. Low density lipoprotein undergoes oxidative modification in vivo. Proc. Natl. Acad. Sci. USA. 86:1372-1376.

5. Boyd, H. C., A. M. Gown, G. Wolfbauer, and A. Chait. 1989. Direct evidence for a protein recognized by a monoclonal antibody against oxidatively modified LDL in atherosclerotic lesions from a Watanabe heritable hyperlipidemic rabbit. Am. J. Pathol. 135:815-825.

6. Jürgens, G., Q. Chen, H. Esterbauer, S. Mair, G. Ledinski, and H. P. Dingers. 1993. Immunostaining of human autopsy aortas with antibodies to modified apolipoprotein B and apolipoprotein (a). Arterioscler. Thromb. 13:16891699.

7. Itabe, H., E. Takeshima, H. Iwasaki, J. Kimura, Y. Yoshida, T. Imanaka and T. Takano. 1994. A monoclonal antibody against oxidized lipoprotein recognizes foam cells in atherosclerotic lesions. J. Biol. Chem. 269:15274-15279.

8. Steinbrecher, U. P., S. Parthasarathy, D. S. Leake, J. L. Witztum, and D. Steinberg. 1984. Modification of low density lipoprotein by endothelial cells involves lipid peroxidation and degradation of low density lipoprotein phospholipids. Proc. Natl. Acad. Sci. USA. 81:3883-3887.

9. Cathcart, M. K., A. K. McNally, and G. M. Chisolm. 1991. Lipoxygenasemediated transformation of human low density lipoprotein to an oxidized and cytotoxic complex. J. Lipid Res. 32:63-70.

10. Quinn, M. T., S. Parthasarathy, L. G. Fong, and D. Steinberg. 1987. Oxidatively modified low density lipoproteins: a potential role in recruitment and retention of monocyte/macrophages during atherogenesis. Proc. Natl. Acad. Sci. USA. 84:2995-2998.

11. Salonen, J. T., S. Ylä-Herttuala, R. Yamamoto, S. Butler, H. Korpela, R. Salonen, K. Nyyssönen, W. Palinski, and J. L. Witztum. 1992. Autoantibody against oxidised LDL and progression of carotid atherosclerosis. Lancet. 339:883887.

12. Ylä-Herttuala, S., W. Palinski, S. W. Butler, S. Picard, D. Steinberg, and J. L. Witztum. 1994. Rabbit and human atherosclerotic lesions contain IgG that recognizes epitopes of oxidized LDL. Arterioscler. Thromb. 14:32-40.

13. Carew, T. E., D. C. Schwenke, and D. Steinberg. 1987. Antiatherogenic effect of probucol unrelated to its hypocholesterolemic effect: evidence that antioxidants in vivo can selectively inhibit low density lipoprotein degradation in macrophage-rich fatty streaks slowing the progression of atherosclerosis in the WHHL rabbit. Proc. Natl. Acad. Sci. USA. 84:7725-7729.

14. Yamamoto, S. 1992. Mammalian lipoxygenases: molecular structures and functions. Biochim. Biophys. Acta. 1128:117-131.

15. Sigal, E. 1991. The molecular biology of mammalian arachidonic acid metabolism. Am. J. Physiol. 260:L13-L28.

16. Rapoport, S. M., and T. Schewe. 1986. The maturational breakdown of mitochondria in reticulocytes. Biochim. Biophys. Acta. 864:471-479.

17. Jessup, W., V. Darley-Usmar, V. O'Leary, and S. Bedwell. 1991. 5Lipoxygenase is not essential in macrophage-mediated oxidation of low-density lipoprotein. Biochem. J. 278:163-169.

18. Folcik, V. A., and M. K. Cathcart. 1993. Assessment of 5-lipoxygenase involvement in human monocyte-mediated LDL oxidation. J. Lipid Res. 34:6979 .

19. Sparrow, C. P., S. Parthasarathy, and D. Steinberg. 1988. Enzymatic modification of low density lipoprotein by purified lipoxygenase plus phospholipase $A_{2}$ mimics cell-mediated oxidative modification. J. Lipid Res. 29:745-753.

20. Belkner, J., R. Wiesner, J. Rathman, J. Barnett, E. Sigal, and H. Kühn. 1993. Oxygenation of lipoproteins by mammalian lipoxygenases. Eur. J. Biochem. 213:251-261.

21. O'Leary, V. J., V. M. Darley-Usmar, L. J. Russell, and D. Stone. 1992. Pro-oxidant effects of lipoxygenase-derived peroxides on the copper-initiated oxidation of low-density lipoprotein. Biochem. J. 282:631-634.

22. Benz, D. J., M. Mol, M. Ezaki, N. Mori-Ito, I. Zelán, A. Miyanohara, T. Friedmann, S. Parthasarathy, D. Steinberg, and J. L. Witztum. 1995. Enhanced levels of lipoperoxides in low density lipoprotein incubated with murine fibroblasts expressing high levels of human 15-lipoxygenase. J. Biol. Chem. In press.

23. Parthasarathy, S., E. Wieland, and D. Steinberg. 1989. A role for endothelial cell lipoxygenase in the oxidative modification of low density lipoprotein. Proc. Natl. Acad. Sci. USA. 86:1046-1050.

24. Rankin, S. M., S. Parthasarathy, and D. Steinberg. 1991. Evidence for a dominant role of lipoxygenase (s) in the oxidation of LDL by mouse peritoneal macrophages. J. Lipid Res. 32:449-456.

25. Derian, C. K., and D. F. Lewis. 1992. Activation of 15-lipoxygenase by low density lipoprotein in vascular endothelial cells. Relationship to the oxidative modification of low density lipoprotein. Prostaglandins Leukotrienes Essent. Fatty Acids. 45:49-57.

26. Ylä-Herttuala, S., M. E. Rosenfeld, S. Parthasarathy, C. K. Glass, E. Sigal J. L. Witztum, and D. Steinberg. 1990. Colocalization of 15-lipoxygenase mRNA and protein with epitopes of oxidized low density lipoprotein in macrophage-rich areas of atherosclerotic lesions. Proc. Natl. Acad Sci. USA. 87:6959-6963.

27. Ylä-Herttuala, S., M. E. Rosenfeld, S. Parthasarathy, E. Sigal, T. Särkioja, J. L. Witztum, and D. Steinberg. 1991. Gene expression in macrophage-rich human atherosclerotic lesions: 15-lipoxygenase and acetyl low density lipoprotein receptor messenger RNA colocalize with oxidation specific lipid-protein adducts. J. Clin. Invest. 87:1146-1152.

28. Simon, T. C., A. N. Makheja, and J. M. Bailey. 1989. Formation of 15 hydroxyeicosatetraenoic acid (15-HETE) as the predominant eicosanoid in aortas from Watanabe heritable hyperlipidemic and cholesterol-fed rabbits. Atherosclerosis. $75: 31-38$.

29. Kühn, H., J. Belkner, S. Zaiss, T. Fährenklemper, and S. Wohlfeil. 1994. Involvement of 15-lipoxygenase in early stages of atherogenesis. J. Exp. Med. 179:1903-1922.

30. Nabel, E. G., G. Plautz, and G. J. Nabel. 1990. Site-specific gene expression in vivo by direct gene transfer into the arterial wall. Science (Wash. DC). 249:1285-1288.

31. Lim, C. S., G. D. Chapman, R. S. Gammon, J. B. Muhlestein, R. P Bauman, R. S. Stack, and J. L. Swain. 1991. Direct in vivo gene transfer into the coronary and peripheral vasculatures of the intact dog. Circulation. 83:20072011.

32. Leclerc, G., D. Gal, S. Takeshita, S. Nikol, L. Weir, and J. M. Isner. 1992 Percutaneous arterial gene transfer in a rabbit model. Efficiency in normal and balloon-dilated atherosclerotic arteries. J. Clin. Invest. 90:936-944.

33. Flugelman, M. Y., M. T. Jaklitsch, K. D. Newman, W. Casscells, G. L. Bratthauer, and D. A. Dichek. 1992. Low level in vivo gene transfer into the arterial wall through a perforated balloon catheter. Circulation. 85:1110-1117.

34. Sparrow, C. P., and J. Olszewski. 1992. Cellular oxidative modification of low density lipoprotein does not require lipoxygenases. Proc. Natl. Acad. Sci. USA. 89:128-131.

35. Sigal, E., C. S. Craik, E. Highland, D. Grundberger, L. L. Costello, R. A. F. Dixon, and J. A. Nadel. 1988. Molecular cloning and primary structure of human 15-lipoxygenase. Biochem. Biophys. Res. Commun. 157:457-464.

36. Kalnis, A., K. Otto, U. Rüther, and B. Müller-Hill. 1983. Sequence of the lacZ gene of E. coli. EMBO (Eur. Mol. Biol. Organ.) J. 2:593-597.

37. Miyanohara, A., M. F. Sharkey, J. L. Witztum, D. Steinberg, and T. Friedmann. 1988. Efficient expression of retroviral vector-transduced human low density lipoprotein (LDL) receptor in LDL receptor-deficient rabbit fibroblasts in vitro. Proc. Natl. Acad. Sci. USA. 85:6538-6542.

38. Ostareck-Lederer, A., D. H. Ostareck, N. Standart, and B. J. Thiele. 1994 Translation of 15 -lipoxygenase mRNA is inhibited by a protein that binds to a repeated sequence in the $3^{\prime}$ untranslated region. EMBO (Eur. Mol. Biol. Organ.) J. 13:1476-1481.

39. Mann, R., R. C. Mulligan, and D. Baltimore. 1983. Construction of a retrovirus packaging mutant and its use to produce helper-free defective retrovirus. Cell. 33:153-159.

40. Miller, A. D., and C. Buttimore. 1986. Redesign of retrovirus packaging cell lines to avoid recombination leading to helper virus production. $\mathrm{Mol}$. Cell. Biol. 6:2895-2902.

41. Cepko, C. 1989. Lineage analysis in the vertebrate nervous system by retrovirus-mediated gene transfer. In Methods in Neurosciences. P. M. Conn editor. Academic Press, New York. 367-392.

42. Rosenfeld, M. E., W. Palinski, S. Ylä-Herttuala, S. Butler, and J. L. Witztum. 1990. Distribution of oxidation specific lipid-protein adducts and apolipoprotein B in atherosclerotic lesions of varying severity from WHHL rabbits Arteriosclerosis. 10:336-349.

43. Tsukada, T., D. Tippens, H. Mar, D. Gordon, R. Ross, and A. M. Gown. 1986. A muscle-actin-specific monoclonal antibody. Am. J. Pathol. 126:51-60.

44. Tsukada, T., M. E. Rosenfeld, R. Ross, and A. M. Gown. 1986. Immunocytochemical analysis of cellular components in lesions of atherosclerosis in Watanabe and fat-fed rabbits using monoclonal antibodies. Arteriosclerosis. 6:601613.

45. Young, S. G., J. L. Witztum, D. C. Casai, L. K. Curtiss, and S. Bernstein 1986. Conservation of the low density lipoprotein receptor-binding domain of apoprotein B: demonstration by a new monoclonal antibody, MB47. Arteriosclerosis. 6:178-188.

46. Ylä-Herttuala, S., T. Nikkari, J. Hirvonen, H. Laaksonen, M. Möttönen, E. Pesonen, J. Raekallio, and H. K. Åkerblom. 1986. Biochemical composition of coronary arteries in Finnish children. Arteriosclerosis. 6:230-236.

47. Nikkari, T., U. Malo-Ranta, T. Hiltunen, O. Jaakkola, and S. Ylä-Herttuala 1995. Monitoring of lipoprotein oxidation by gas chromatographic analysis of hydroxy fatty acids. J. Lipid Res. 36:200-207.

48. Ylä-Herttuala, S. 1994. Role of lipid and lipoprotein oxidation in the pathogenesis of atherosclerosis. Drugs Today. 30:507-514.

49. Schwenke, D. C., and T. E. Carew. 1989. Initiation of atherosclerotic lesions in cholesterol fed rabbits. II. Selective retention of LDL vs. selective increases in LDL permeability in susceptible sites of arteries. Arteriosclerosis. 9:908-918 